\title{
ABSTRACTS OF MEMOIRS \\ RECORDING WORK DONE AT THE PLYMOUTH LABORATORY.
}

\section{The Relation between Light and Pigment-formation in Crenilabrus and Hippolyte. By Prof. F. W. Gamble, F.R.S. (Quart. Jour. Micros. Science, Vol. LV, Pt. 3, 1910.)}

THE work on which this paper is based was carried out at Plymouth in 1908 and 1909. The two species on which the main results were investigated were Crenilabrus melops and Hippolyte varians. Backgrounds of weed and of painted glass were employed in order to test the influence of reflected light. Light-filters transmitting red and green respectively were used to determine the result of subjecting Hippolyte to diffused monochromatic light.

The following are the chief results:-

(1) Crenilabrus. The effect of light reflected from backgrounds of weeds and diluted with white light is different from the effect of light transmitted through the same weeds and not largely diluted with white light. In the former case the young animals generally assumed the tint of their surroundings; in the latter the dominant colouring was that complementary to the brightest part of the transmitted spectrum.

(2) Hippolyte. Any female of this variably coloured prawn throws larve which are constant in coloration with the exception of the broods of certain green parents. In other cases the colour (red) of the Zoeae varies in intensity at the time of hatching with the amount of red pigment in the female.

Green females throw one of three kinds of larve: (1) all red; (2) colourless; or (3) a mixture of red and colourless in the proportion. of 3 to 1 .

The red larval pigment develops in the absence of light. The origin of the yellow pigment has not been timed, but post-larval specimens (4-5 mm. long) if kept in darkness develop into brown specimens.

In pure green light similar (nearly colourless) specimens develop into crimson specimens. The red and yellow pigments disappear.

In pure red light the yellow pigment develops, and this together with a variable amount of diffuse blue colouring give a green tint, or a yellowish one. The colour of the food has apparently some influence upon the result. 
On a red background and on a green background in white light Hippolyte become orange and green respectively.

The production of sympathetic colouring in the shallower coastal waters is explained as a background effect. The production of crimson Hippolyte (and possibly of reddish varieties of other marine animals) in deeper water is explained as due to diffused green light.

There is no evidence that the pigments of the algal food are the sources of the pigments in Hippolyte varians.

F. W. G.

\section{The Reproduction and Early Development of Laminaria digitata and Laminaria saccharina. By G. H. Drew. Ann. Bot., Vol. XXIV, No. XcIII., January, 1910, p. 177.}

Laminaria digitata and L. saccharina are among the commonest seaweeds found on the coasts of the British Isles; they form the greater part of the "kelp" which is collected in some places for commercial purposes.

In the autumn and winter dark brown patches appear near the extremities of the broad flattened fronds, and in these the reproductive cells are formed. When ripe, small pieces of these reproductive areas were placed in a special culture solution (Allen and Nelson's modification of Miquel's solution), and it was found that an immense number of minute, free swimming cells were liberated. These cells each have two flagella, by means of which they are enabled to swim actively, and they show a tendency to move towards any source of light. Though all are exactly similar in appearance, yet these cells must be regarded as the sexual cells of the plant. After a time they fuse in pairs, lose their flagella, and settle to the bottom of the culture fluid. A series of changes then takes place resulting in the formation of a chain of cells possessing colouring matter, and apparently capable of absorbing nutrition, and of growth. This chain of cells can be considered as a separate plant, which though of an extremely rudimentary type, yet has an independent existence. Eventually any cell of the chain may give rise directly to a young Laminaria plant.

Thus in the life cycle of Laminaria, an alternation of generations occurs: the Laminaria plant represents the sexual phase, and the microscopic chain of cells above mentioned represents the asexual phase.

G. H.D. 
Some Notes on Parasitic and Other Diseases of Fish. By G. H. Drew. Parasitology, Vol. II, No. 3, September, 1909, p. 193; second series, Vol. III, No. 1, April, 1910, p. 54.

AN examination of a number of diseased fish was undertaken primarily with the object of finding cancerous growths. Many of the specimens were obtained by the s.s. Huxley in the North Sea.

Four cases of cancer were found resembling in appearance and structure malignant cancerous growths in man. Two of these originated in the pancreas of two specimens of plajce, and two in the livers of rainbow trout. There seems no reason to suppose that these growths are not in every way comparable to true carcinoma as found in man. One case of a superficial growth in a dog-fish was found, closely resembling the growths known as endotheliomata, which are generally included in the term "cancer." A number of cases of "benign" tumours were found (fibromata, myxo-fibromata, etc.), chiefly in plaice and salmon, and these also showed the closest resemblance to similar tumours in human beings. It thus seems probable that, whatever may be the cause of cancer and other tumours in man, the same cause may be operative in the production of similar growths in fish.

Several cases of disease due to sporozoon parasites were investigated, and two new species of sporozoa were described.

A number of cases of an affection of the swim-bladders of trout, resulting in the death of a large number of fish, were investigated. It was found that nematode worms made their way from the intestine into the swim-bladder by burrowing through the tissues, and carried bacteria with them, which set up an acute septic inflammation.

An outbreak of a contagious disease among fish in the Hertfordshire Colne was also investigated, and it was recognized as a recrudescence of the "salmon disease," in this case attacking fish of many different species. The specific bacteria were isolated, and also the white filamentous fungus, which grows freely on the lesions caused by the bacteria, was identified.

G.H.D. 
Some Points in the Physiology of Lamellibranch Blood Corpuscles. By G. H. Drew. Quar. Jour. Micro. Sci., Vol. LIV, Part 4, Feb. ruary, 1910 , p. 605 .

The Origin and Formation of Fibrous Tissue as a Reaction to Injury in Pecten maximus. By G. $\mathbf{H}$. Drew and W. De Morgan. Quar. Jour. Micro. Sci., Vol. LV, Part 3, September, 1910, p. 595.

THEsE investigations were carried out as a necessary preliminary to further work of an experimental nature on the mode of origin of tumours. Most of the work was done on the common cockle and scallop.

The different sorts of corpuscles present in the blood were described, and it was shown that they were capable of ingesting, and so destroying, bacteria; thus protecting the animal from bacterial attacks. It was also shown that if the animal were wounded, so that any blood escaped, the corpuscles adhered to the injured surfaces and then sent out long, slender processes which would join up with similar processes from corpuscles on the other side of the wound. A network is thus formed in which other corpscules become entangled and so block up the opening of the wound. Finally, the protoplasmic strands forming the network contract, and so draw together the injured surfaces, which soon heal up.

The formation of fibrous tissue as a reaction to injury, and the consequent healing of wounds by "scar-tissue" formation, was also studied in detail. It was shown that any injurious foreign body which was implanted into the tissues of the animal was rapidly surrounded by an agglutinated layer of blood corpuscles, and that these were soon replaced by a dense mass of fibrous tissue. The foreign body thus becomes completely surrounded by a protective fibrous capsule, which, by shutting it off from the neighbouring tissues, tends to prevent its injurious action from spreading. It is perhaps an interesting point in the study of Evolution, to note that the process of "scar-tissue" formation, by which such animals as the scallops are enabled to recover from injuries, differs only in detail from the similar process which occurs in the highest types.

G. H.D. 